\title{
The Indispensability of Critique: Reflections on Bearing Witness to Mental Health Discourse
}

\author{
Simon Adam ${ }^{1}$, Cheryl van Daalen-Smith ${ }^{2}$, Linda Juergensen ${ }^{1}$ \\ ${ }^{1}$ York University, School of Nursing, 4700 Keele Street, Toronto, Ontario, Canada. \\ ${ }^{2}$ York University, School of Nursing, School of Gender, Sexuality, and Women's Studies, 4700 \\ Keele Street, Toronto, Ontario, Canada.
}

Cite as: CJCND 2019, 1(1), 39-48

\begin{abstract}
Reflecting on two mental health examples from our practice, we demonstrate how in the instances that critique is absent, the results can be dangerous. Drawing on Foucauldian theory, we propose the idea of critique, known as the vigilant tempering of governance (or the 'conduct of conduct'). We advance that critique is an indispensable health resource for the practicing mental health nurse and for nursing more broadly, without which nursing risks participating in the reproduction of hegemonic discourses and practices. Critique, in this paper, is theorized as a tool to be included in the nurse's repertoire, that which can unlock a variety of ontological and epistemological possibilities. We discuss some reasons why nursing critique is constrained and offer questions for further reflection and critical consideration.
\end{abstract}

Keywords: Critique; Critical theory; Michel Foucault; Mental health.

A compelling phenomenon is fast under way in mental health discourse. Largely contentious, this phenomenon appears to be marked by a growing plurality of emerging perspectives and approaches arising out of resistance to the medicalization of social problems (Green, 2018). This contentious space, articulated at the juncture of biomedical psychiatry and critical psychiatry movements is the location with which we open up this article. It is likewise the location in which we situate our reflections as critical mental health theorists and practitioners.

In this article, we focus on the idea of critique (Foucault, 2007) as an indispensable health resource, one without which the mental health system risks stagnation in biomedical discourses and a lack of person-centered care. Beyond mental health discourse, critique for nursing is necessary in order to question institutional regimes of practice and challenge the reproduction of potentially unethical care. Critique provides nursing with a key to unlocking the possibilities of analysis and revealing arrays of ontological and epistemological multiplicity. In example, we offer two case studies from our practice. The first relates to clinical practice, the second relates to nursing education. Both represent common experiences often found in mental health clinical and pedagogical settings. We share how we process(ed) these examples, including our emerging questions around the perpetual absence of critique within practice and educational settings. We then situate these examples within the critical mental health movement and draw on critical theory. Specifically, we make use of Michel Foucault's work on critique and critical thought (2007) to make linkages between what we witness in practice and the direction in which we could go as clinicians, educators, and person-centred advocates. 


\section{Methodological and Ethical Considerations}

We adopt elements of Carolyn Ellis' (2004) autoethnographic traditions. Autoethnography is a qualitative methodology that makes use of anecdotal self-reflective writing in order to interrogate and more deeply understand social and historical phenomena. To that effect, we centre on two journal entries that to various degrees document our lived

experience as clinicians and educators as we interacted with mental health discourse and practice. The phenomenon we focus on is our grappling with the medicalization/criminalization of mental health as we go about our clinical and teaching work as critical mental health theorists.

In gathering, documenting, and reporting these data, we ensured that no unique identifiers (names, locations, descriptions, highly unique events) were used so as to preserve the anonymity of people and institutions. Pseudonyms were assigned to people and some information (not consequential to our analysis) was also changed in order to more rigorously ensure the protection of identity. The research required no ethical review, given that we draw the data from our own documented lived experiences, with the abovenoted privacy and confidentiality protection mechanisms in place.

\section{Witnessing a Troubling Disparity in Care: The Story of Craig}

The first example is taken from a reflective journal entry. It describes a clinical practice scenario in a Canadian hospital where the journal entry author worked as a clinician. It is this experience, journaled below, that became the pivotal turning point by which the writer became a mental health activist.

I remember it like it was yesterday. Craig. 13 years old, admitted to the psychiatric unit where I was working part-time. He wasn't walking, talking, toileting or eating. He wore a white baseball hat, sunglasses, and his head was bowed downwards. He had, for all intents and purposes, shut down. He had retreated inwards. To me, I thought we would provide him with a reprieve where he would, at his own pace, find his way back out. I admitted him, called the IV team, and spoke gently with him despite receiving no reply. His father lumbered over and supervised all interactions, including those with his wife, whose affect was flat and sullen. Craig's siblings uncharacteristically clung to the nurses on the unit, setting off warning bells in my pediatric nursing heart. I provided report to the night charge nurse and left. And then...

When I returned in 72 hours, I learned that he had been sent quietly to an adjoining hospital for electroconvulsive therapy (ECT), with an additional procedure scheduled for later today. I asked in report whether he had been seen by any social workers and whether any investigation into abuse had been commenced? Later that day, the head nurse took me into the utility room and asked me why I had to "bring that feminist stuff here, onto the unit?"

Soon, Craig was eating, talking, walking, and his baseball and sunglasses had had been removed. His mood fluctuated between guarded and guardedly boisterous. Transported via basement halls to an adjoining adult hospital in the early morning, I learned that Craig received electroshock approximately six times. I looked in the chart and found no indication that he had received ECT.

Two floors down, I had recently worked with a similarly-aged young man, where we did everything we could to ensure that nothing would touch him that could possibly irritate or injure his skin. We removed the visiting hour rules, linked him with play therapy, an occupational therapist, and school teachers. We ensured his parents and siblings had their own supportive listener to process things with.

Why the difference in approach? The only discernible difference was that boy two flights down had cancer and Craig was on the hospital's psychiatric unit.

The day he was discharged is etched in my mind. He wore a brown corduroy jacket and looked back over his shoulder before he left the unit. 
What was witnessed raised a number of questions: Why was there no notation in the chart? Was this

intentional? Why was the asking about the possibility of abuse considered feminist? How could it be missed that what was happening to Craig was not likely in

his best interest? And worse, was my being taken aside an example of an expectation to dismiss the

maleficent? And why the rush? Why was he not afforded the time to develop trust with at least one skilled practitioner so that he, in his own way, might be able to help us understand his needs, fears, and reasons for retreating? Why such a difference in approach between two boys of equal intrinsic value? Is that the core issue? Is it that the boy with cancer was 'blameless' whereas the boy admitted to psychiatry was somehow not?

Victim-blaming approaches that suggest this was simply bad parenting, a weird kid, or an 'odd-ball' family (a narrative that dominated the team discussions about Craig and his family) are a symptom of the wide-spread adoption of the Diagnostic and Statistical Manual of Mental Disorders' (DSM) focus on categorizing abnormality (Breggin, 1991; Burstow, 2005; 2015). The DSM individualizes scenarios, negating the need to ask ourselves: "Yes, but why?" Unpacking this situation steers us away from surfacelevel suppositions about a 'weird' kid and his 'weird' family. It involves asking complex questions. It involves avoiding simplistic surface-level assumptions that give way to short term 'solutions.' Was the problem to be solved that he was not walking, talking, toileting, or eating, or was it broader? Rather than viewing his mother as odd or as a bad mother because her children were unusually clingy (implying failed maternal attachment or some sort of other pathologization of mothers), asking critical questions means that we search to understand the myriad of reasons underlying the mother's flat affect. This includes understanding the many possible dynamics in a family that might perhaps explain why a father is speaking on behalf of his wife, her downcast eyes, the clinginess of the other children, and first and foremost, the reasons why Craig retreated inwards. And all of this could not happen quickly.

\section{The Violent Mental Patient: Reproducing the Myth}

The second example (next page) is also an excerpt from a journal entry comprising a brief composite of a collection of responses of undergraduate nursing students as they engaged in dialogue with one of the authors. This recent journal entry comprises extracted recollections from over a decade of teaching experience, during which these responses and ideas were gathered in a reflective writing of one of the authors. 
In this entry, I reflect on two distinct but related experiences I had over the last several years. It is the fall of 2018 , and as I sit here and recollect past interactions with my nursing students, specifically those that relate to conversations around mental health and mental illness, I cannot help but problematize the implications of such experiences.

The first involves a group seminar I led almost a decade ago, of fourth-year undergraduate nursing students, during which I facilitated a discussion on the media's portrayal of mental illness by using a newspaper clipping as an example. Before engaging in a critical discourse analysis of the news source, I asked the group of eight students to give me their definitions of mental health. In a rather interesting discussion, what surfaced were such ideas as "stability," "balance," "productivity," "neurotransmitters," "family history," and "the brain." Among other related concepts, students drew on medical diagnosis, interventions, "treatment," and "recovery." Some students even alluded to the link between "unpredictability of behaviour" and violence. This is a fitting segue, given the seminar focused on a critical discussion on the media's perpetual reproduction of the myth of the violent mental patient.

A second, more recent experience involves my leading a large lecture for third-year undergraduate nursing students. The topic is community mental health. I had just finished presenting a short discussion on the mad community and the antipsychiatry movement, emphasizing the latter's rejection of psychiatry as a legitimate medical specialty and casting doubt on the validity of psychiatric diagnoses. A student raised his hand and asked: "but what about the chemical imbalance and neurotransmitter science?" Other students joined this discussion, asking questions, pointing to the difficulty (impossibility for some) to accept that mental illnessgiven it is a medical issue-lacks the scientific validity given to organic medical diagnoses. The extent of these students" criticality found its limits at such ideas as "stigma" and "patient-centeredness," often using diagnosis and recovery-based language such as "patient," "illness," and "care."

Recalling some recent statements, the following distinctly come to mind:

"Diagnosis helps us understand what the problem is."

"I can't wrap my head around that mental illness is not a disease."

"What about people whose behaviour is just bizarre and those who are violent?"

We can potentially gather by some of the lexical choices made by the students, that mental illness/health is theorized in a rather biomedical way. Highly evident in the students' general responses are discourses of biomedicine, risk, violence, and problem-based understandings of mental illness and mental health.

What is most worrisome about the implications of these student responses is neither the biomedical default with which they explained mental health nor the ready-made linkages made between mental health and social "balance," troubling though that is. What is most unsettling is a sort of natural correlation between the 'mentally ill' and "behavioural unpredictability," while linking it to violence. Despite a robust critical discussion on stigma that preceded this lecture, students were still found to inherently label, categorize, and segregate people and communities into social "misfits" based on a mental illness diagnosis and based on behavioural manifestation.
If we momentarily step back and reflect on how it is that students, time and again, come to articulate mental health in such biomedical and rigid ways and in such ways that inherently reproduce problematic understandings of people and communities who suffer disruptions in their mental health, we must ask some complex and difficult questions. We must extend our questions beyond the focus on individual nurses/nursing students and individual patient care units. We must direct our critical gaze at the level of the institution of psychiatry and the discourses that support it and subsequently give rise to such malevolent practices. Not dissimilar to the questions we ask around Craig's case, here too, these student responses beg an investigation that delves beyond individual student 'attitudes' and 'knowledge,' and the subsequent judgements they rendered. 


\section{Mental Health: An Alternate Epistemology}

While we-and other nurses and nursing scholars-have begun to take issue with mental health and psychiatric practices, we are not alone. Through decades of clinical practice, higher education,

research, and activism work, we have come to learn that despite the assumed legitimacy and the

'efficiency' of institutionalized mental health services, there is a counter-narrative that likewise critiques and sometimes rejects these services. It is a narrative that advances critical perspectives deployed from lived experience, advocacy, and activism.

While the nursing academy is aggressively preparing nurses heavily immersed in biomedical mental health discourse (Adam, 2017), a counter-discourse is gaining momentum in talking back to psychiatric hegemony. This discourse is modestly buttressed by the voices of psychiatric survivors (Andre, 2009; Chamberlin, 1978; Funk, 1998) and largely by community activists and medical and nursing scholars (Breggin, 2008; Hagen \& Nixon, 2011; van DaalenSmith, 2011; van Daalen-Smith et al., 2014).

A number of works has de-legitimized psychiatric diagnoses while calling into question the appropriateness of psychiatry's authority over human behaviour (Burstow, 2015; Hagen 2007; Hagen \& Nixon, 2011). Others have suggested that psychiatric logic is predicated on linguistic theory such as semantics and metaphors (Burstow, 2015; Edelman, 1974; Szasz, 1996 \& 2003), and practices of social control (Burstow, 2015; Chapman, 2014; Fabris, 2011; Foucault, 1988; Minkowitz, 2014). Labelling theorists have found stigma as an inherent characteristic of psychiatric diagnoses (Goffman, 1961). Psychiatric drugs have been shown to cause irreversible chemical imbalances in the body, including brain damage (Breggin, 2008; Burstow, 2015; Lehmann, 1998), and were found to be implicated in an institutionalpolitical business complex, rampant with private interests having little to do with patient well-being (Breggin, 2008; Burstow, 2015; Healy, 2012; Whitaker, 2002). Disability has also been documented as a direct cause of such psychiatric treatments as neuroleptic medications and electroshock (Breggin, 2008; Fabris, 2011; Funk, 1998; Sackeim, Prudic, Fuller, Kielp, Lavori, \& Olfson, 2007). Further to that effect, Harrow and Jobe (2007) established that those diagnosed with schizophrenia thrive better socially without medication than those on antipsychotics. Critiques of psychiatric interventions have also been documented by the United Nations as degrading and undignified (United Nations, 2013). The damage of other psychiatric treatments is also well documented (Andre 2009; Burstow, 2006; Funk, 1998; van DaalenSmith, 2011; van Daalen-Smith et al., 2014).

These critical perspectives are so much an established position that plausible alternatives to psychiatry have been theorized (Burstow, 2015; Chamberlin, 1978) and successfully implemented (Breggin, 2017; Oaks, 2011; Stastny \& Lehmann, 2007). For example, Bonnie Burstow sketches out the beginnings of a world without psychiatry. She outlines, using several scenarios of people in various states of distress, what a community-based, non-professionalized, nonpathologizing approach to 'care' might look like. She does this with great complexity and careful attention to the dismantling of psychiatric hegemony. Peter Breggin-a practicing psychiatrist-has gone a step further and implemented what has come to be internationally known as the Centre for the Study of Empathic Therapy, Education, and Living. In his own words, Peter Breggin describes empathic therapy as a practice that:

recognizes, welcomes and treasures the individuality, personhood, identity, spirit or soul of the other human being in all its shared and unique aspects.

Empathic therapies offer a caring, understanding and empowering attitude toward the individual's emotional struggles, aspirations and personal growth. They promote the individual's inherent human rights to life, liberty and the pursuit of happiness. They respect the autonomy, personal responsibility and freedom of the person.

(http://www.empathictherapy.org/What-IsEmpathic-Therapy-.html)

Over and again, psychiatric survivors have expressed the negative experiences they had and continue to have with psychiatric care. Their narrative populates a growing body of evidence that has compelled clinicians, health researchers, and legislators to pay attention. The lived consequences for the individual range between a dissatisfaction with the care to experiences of overt violence and trauma (Andre, 2009; Chamberlin, 1978; Funk, 1998). According to these and other survivors, at stake is their dignity, their personhood, their minds, their bodies, and their lives beyond psychiatric care-with their families, friends, the workplace, and society at large. For us, at stake is the nurse-client relationship: A relationship grounded 
in the stalwart protection of the patient's safety, dignity, and human rights.

Notwithstanding this critical movement, nursing remains near-silent on matters of madness and psychiatric survivorship perspectives-evident in its undergraduate education (Adam, 2017) and from our observations in our own practice-a perspective without which mental health nursing remains largely biomedically-oriented, while marginalizing other forms of knowledge. Symptomatic of this silence is the sort of practices that arise in clinical and educational settings in nursing, much like those represented by the two examples we discuss above. Nursing has much to learn from this critical movement, especially from the mass of voices of survivor-consumer groups and their advocates. That this critical movement exists while nursing mental health care continues to be biomedically delivered is evidence that critique in nursing is at best inadequate.

Minimally, nursing practice ought to represent what the recipients of care-those whose wellbeing we have been entrusted to ensure-deem helpful. How then, do nurses begin to work towards this sort of practice? How can nursing draw on this critical movement and render material change in mental health nursing discourse and practice? More broadly, what tools can be added to the nurse's repertoire to enable the nurse to engage in this sort of analysis, not just in mental health settings, but in all facets of nursing work? We argue that the only sustainable way for nursing to do this is to equip nurses with an enduring method of critique, the sort of critique that demands of us complex, difficult, and 'unwelcome' questions. It is the sort of critique out of which much of the works cited above emerged. In the next sections, we offer some possible directions, beginning with a discussion on critical thought while drawing on critical theory.

\section{Thinking Beyond the Bedrails: Critique as a Virtue}

Foucault (2007) defines critique as "the art of not being governed quite so much" (p. 45). From a Foucauldian perspective, 'government' refers to the "conduct of conduct" (Gordon, 1991, p. 1). Questions around governance, therefore, require an analytics of government, a critical reflection about how institutional rationalities and practices shape nurses' conduct and, in turn, how nurses are involved in shaping the conduct of others (Dean, 2010). In short, we refer to the idea of governance as the conduct of conduct, that which is deployed by institutions steeped in such powerful discourses as psychiatry, pharmacology, biomedicine, and so on. The idea of "not so much" is an important one for our consideration, as it suggests that governance in and of itself is not necessarily a negative force. Along with the acceptance that to a certain degree, governance is necessary, in an effort to avoid 'dangerousness' of some discourses, however, we must practice vigilance. Not being governed quite so much, thus, involves the tempering of such governance, ostensibly through a critique of what conduct should or should not be tolerated. Foucault (2000) writes, "the suffering of men [sic] must never be a silent residue of policy. It grounds an absolute right to speak up to those who hold power" (pp. 474-475). He later provides us with two anchoring points that are relevant to how we see nurses engaging in critique (Foucault, 2007). The first is the refusal to accept unjust laws that by the virtue of their application, "they hide a fundamental illegitimacy" (p. 266). The second point is to do with not accepting as true what an authority says is true simply because it is told by an authority.

At first glance, these points may seem rudimentary, especially to a conscientious, ethically-grounded practitioner, that seeking justice and questioning facevalue authoritative claims are an achievable professional expectation of the nurse. On closer examination, however, asking these of nurses, especially those working within mental health and psychiatric settings may prove more difficult than meets the eye. For example, while many nursing students and indeed their clinical instructors experience moral distress during psychiatric clinical rotations, they find they have no recourse but to go along in order to maintain the placement (Wojtowicz, Hagen \& van Daalen-Smith, 2013). The students from the second journal entry excerpt, while articulating rather problematic conceptualizations of mental health, ostensibly did so in the best interest of the hypothetical patient. Theirs was an analysis that justified labelling and stigmatization (however invisible to them), because by way of labelling/diagnosing, they also entered the patient into what they believed is a helpful medical discourse. The students, evident in one response, also felt it important to label/diagnose in order "understand" what the problem was. This is all rooted in the desire and the commitment to help people, particularly those who have been constructed as suffering from a brain-based chemical/medical condition.

The nurses who participated in sending Craig to ECT operated within an institutional mandate constructed to give the illusion of beneficence-that all else has failed in the treatment of his depression, that subjecting him to a violent intervention is an act deemed to be done in his best interest. It is this level on which most nursing 
clinicians have been made to work, often embedded in an institutional-discursive system of efficiency and hyper-governance (Adam, 2014; Adam, 2017). This system would find that mental health nurses comply with a set of institutional regulations, governed by powerful psychiatric and legislative texts that navigate their practice and their consciousness in a particular way (Adam, 2017; Wojtowicz, Hagen \& van DaalenSmith, 2013).

Nurses, alternatively, might possess the moral character and courage to engage in the sort of critique Foucault advances. For example, the nurses in the case of Chris, even those who might have acted in rather violent ways, did so in accordance with an ethical commitment to 'helping' someone deemed to be in a state of severe distress. While nurses do possess the ability to engage and act in ethically sound ways, their ethical reasoning appears to be constrained by institutional reasoning. Through critique, however, and by way of unpacking the knowledge and practices that are privileged in an institution, nurses can simultaneously uncover the professional, sociocultural, and historical perspectives that have been suppressed under the current regimes of mental health care and make them available to individual and collective interrogation (Dean, 2010).

\section{What is Constraining Critique in Nursing?}

It would be politically and ethically naïve to suggest that nurses-or any practitioners from the helping professions-intentionally engage in maleficent practice. It is not refuted here, that nurses deliberately enter practice with a genuine desire to help others. However, and while the proverbial nursing heart is in the right place, upon entry and subsequent long-term immersion in institutional discourses that measure success in terms of biomedical outcomes and social conformity and productivity, nurse's priorities and practices become constrained (Adam, 2011). Moreover, nursing practice-education includedappears to also be caught within a nexus of power, namely articulated by relations between medicine, nursing, and Big Pharma (Adam, 2014; Adam, 2017). These relations, substructed by powerful discourses, substantially navigate nursing work in a way to respond to institutional (hospital, clinic, university) (Adam \& Juergensen, 2019) and discursive (psychiatry, Big Pharma, managerial) interests (Adam, 2014).

Without critique, those nurses who find themselves at the juncture between biomedical psychiatry and critical mental health work will be minimally curious about problematic psychiatric care, and at best, in moral distress resulting from such curiosity. While there is much work to be done in order to extend nursing's gaze 'beyond the bedrails,' emancipatory critical thought is possible, as is a new way of doing mental health nursing discourse and practice. We agree with Foucault's conception that critique is (or ought to be) a virtue, a constant striving for moral excellence (Foucault, 2007), woven within the character of the nurse. Rooted in a relational practice, critique as an ethical orientation, in our view, can effectively equip nurses to work towards not being governed quite so much.

\section{Closing Remarks}

Exemplified in the two reflective journal excerpts described in this paper is the indispensability of critique. The two excerpts illuminate moral tension between the medicalization of mental health care and nursing's ethical imperative to infuse professional practice with a concern for preserving human dignity, preventing harm and promoting social justice (Canadian Nurses Association [CNA], 2017; Edwards \& MacLean Davison, 2008). In sharing our critical reflections and our theorizing, we aimed to illustrate the power of nurse-led critical reflection and its potential to advance nursing discourse and practice.

Specifically, we demonstrate how questioning dominant discourses simultaneously opens up the possibility of considering counter-discourses that challenge the status quo. Despite the tensions that might arise, we submit that critique as reflection is not merely criticism, but a positive force for questioning practice and advocating for change. As Foucault (1983) once argued:

My point is not that everything is bad,
but that everything is dangerous, which
is not exactly the same as bad. If
everything is dangerous, then we
always have something to do. So, my
position leads not to apathy but to
hyper-and pessimistic-activism. (p.
231).

Critique can subsequently be viewed as a form of 'vigilance,' a continuous 'checking-in' with ourselves and others about the effects of our conduct. It is a conscientiousness towards recognizing both the strengths and limitations of institutional policies and practices and mitigating their dangers. We offer these examples to illustrate the value of critique as a tool for reflecting on assumed truths, taking risks to ask 
unwelcome questions, leading a collective pause, and feeling comfortable admitting we may not have all the answers.

Critique, we suggest, is an indispensable tool for understanding tensions, inspiring strategic dialogue about the direction of nursing work, and mobilizing care that accounts not only for institutional goals, but also considers nursing and client perspectives in what is morally sound. It disrupts the status quo by challenging taken-for-granted assumptions, directing us to look beyond what becomes routinized. Through the deconstruction of competing discourses circulating as truth, critique enables structural thinking, facilitating an exploration of wide berth. If we have the courage to embrace critique as an indispensable resource, the key to unlocking an array of ontological and epistemological possibilities is ours to hold, we just need to turn it.

\section{References}

Adam, S. (2017). Crazy making: The institutional relations of undergraduate nursing in the reproduction of biomedical psychiatry. International Journal of Nursing Education Scholarship, 14(1), DOI: https://doi.org/10.1515/ijnes-2017-0071

Adam, S. (2014). From subservience to resistance: Nursing versus psychiatry. In B. Burstow, B. LeFrançois, \& S. Diamond (Eds), Psychiatry disrupted: Theorizing resistance and crafting the (r)evolution, (pp. 65-76). Montreal, Canada: McGill-Queens University Press.

Adam, S. (2011). Elder care in an emergency department: How does disparity in practice come to be? (Master's thesis). Library and Archives Canada.

Adam, S. \& Juergensen, L. (2019). Critical thinking as a virtue: The case of mental health nursing education. Nurse Education in Practice, 38.

Andre, L. (2009). Doctors of deception: What they don't want you to know about shock treatment. New Jersey: Rutgers University Press.
Breggin, P. (Ed.). (2008). Brain-disabling treatments in psychiatry: Drugs, electroshock, and the psychopharmaceutical complex. New York: Springer Publishing.

Breggin, P. (1991). Toxic psychiatry: Why therapy, empathy, and love must replace the drugs, electroshock, and biomedical theories of the "new psychiatry." New York: St. Martin's Press.

Breggin, P. (2017). Centre for the study of empathic therapy, education, and living. Retrieved from http://www.empathictherapy.org/index.html \#.WA46WeUrLxk.

Burstow, B. (2005). A critique of posttraumatic stress disorder and the DSM. Journal of Humanistic Psychology, 45(4), 429-445.

Burstow, B. (2006). Electroshock as a form of violence against women. Violence Against Women, 12(2), 372-392.

Burstow, B. (2015). Psychiatry and the business of madness: An ethical and epistemological accounting. Toronto: Palgrave MacMillan.

Chamberlin, J. (1978). On our own: Patient controlled alternatives to the mental health system. New York: Haworth Press.

Chapman, C. (2014). Becoming perpetrator: How I came to accept restraining and confining disabled Aboriginal children. In B. Burstow, B. LeFrançois, \& S. Diamond (Eds.), Psychiatry disrupted: Theorizing resistance and crafting the (r)evolution (pp. 16-33). Montreal: McGill-Queen's University Press.

CNA. (2017). Code of ethics for Registered Nurses, 2017 Edition. Ottawa: Canadian Nurses Association.

Dean, M. (2010). Governmentality: Power and rule in modern society, 2nd Edition. Los Angeles: Sage.

Edelman, M. (1974). The political language of the helping professions. Politics and Society, 4, 295-310.

Edwards, N. \& MacLean Davison, C. (2008). Social justice and core competencies for Public Health: Improving the fit. Canadian Journal of Public Health, 99(2), 130-132.

Ellis, Carolyn. (2004). The Ethnographic I: A methodological novel about autoethnography. Walnut Creek: AltaMira Press. 
Fabris, E. (2011). Tranquil prisons: Chemical incarceration under community treatment orders. Toronto: University of Toronto Press.

Foucault, M. (1983). On the geneology of ethics: An overview of work in progress,' in H. L. Dreyfus \& P. Rabinow (Eds.), Michel Foucault: Beyond Structuralism and Hermeneutics (2nd Edition). Chicago: The University of Chicago Press.

Foucault, M. (1988). Madness and civilization: A history of insanity in the age of reason. New York: Vintage Books.

Foucault, M. (2000). Confronting governments: Human rights. In J. Faubion (Ed.), Essential works of Foucault (Volume 3): Power (pp. 474-475). New York: New Press.

Foucault, M. (2007). The politics of truth. South Pasadena: Semiotext(e).

Funk, W. (1998). What difference does it make: A journey of a soul survivor. Cranbrook: Wild Flower Publishing.

Goffman, E. (1961). Asylums: Essays on the social situation of mental patients and other inmates. New York: Anchor Books.

Gordon, C. (1991). Governmental rationality: An introduction. In G. Burchell, C. Gordon \& P. Miller (Eds.), The Foucault effect: Studies in governmentality (pp. 1-52). Chicago: The University of Chicago Press.

Green, T. (2018). What a society designed for wellbeing looks like. Yes! Magazine. Retrieved from

https://www.yesmagazine.org/issues/mentalhealth/what-a-society-design-for-well-beinglooks-like-20180912

Hagen, B. (2007). Measuring melancholy: A critique of the Beck Depression Inventory and its use in mental health nursing. International Journal of Mental Health Nursing, 16, 108115.

Hagen, B. \& Nixon, G. (2011). Spider in a jar: Women who have recovered from psychosis and their experience of the mental health care system. Ethical Human Psychology and Psychiatry, 13(1), 47-63.

Harrow, M. \& Jobe, T. H. (2007). Factors in outcome and recovery in schizophrenic patients not on antipsychotic medications. The Journal of Nervous and Mental Diseases, 195, 406414.

Healy, D. (2012). Pharmageddon. Los Angeles: University of California Press.

Lehmann, P. (1998). Coming off psychiatric drugs: Successful withdrawal from neuroleptics, antidepressants, lithium, carbamazepine, and tranquilizers. Berlin: Peter Lehmann Publishing.

Minkowitz, T. (2014). Convention on the rights of persons with disabilities and liberation from psychiatric oppression. In B. Burstow, B. LeFrançois, \& S. Diamond (Eds.), Psychiatry disrupted: Theorizing resistance and crafting the (r)evolution (pp. 129-144). Montreal: McGill-Queen's University Press.

Oaks, W. (2011). The moral imperative for dialogue with organizations of survivors of coerced psychiatric human rights violations. In T. W. Kallert, J. E. Mezzich, \& J. Monahan (Eds.), Coercive treatment in psychiatry: Clinical, legal and ethical aspects (pp. 187-209). Sussex: John Wiley \& Sons.

Sackeim, H., Prudic, J., Fuller, R., Kielp, J., Lavori, P, \& Olfson, M. (2007). The cognitive effects of electroconvulsive therapy in community settings. Neuropsychopharmacology, 32, 244-255.

Stastny, P. \& Lehmann, P. (2007). (Eds.), Alternatives beyond psychiatry. Berlin: Peter Lehmann Publishing.

Szasz, T. S. (1996). The meaning of mind: Language, morality, and neuroscience. Syracuse: Syracuse University Press.

Szasz, T. S. (2003). A lexicon of lunacy: Metaphoric malady, moral responsibility, and psychiatry. New Brunswick: Transaction Publishers.

United Nations. (2013). Special rapporteur on torture and other cruel, inhuman or degrading treatment or punishment: 22nd session of the Human Rights Council, agenda item 3, Geneva. Retrieved from http://www.ohchr.org/Documents/HRBodies /HRCouncil/RegularSession/Session22/A.H RC.22.53_English.pdf

van Daalen-Smith, C. (2011). Waiting for Oblivion: Women's experiences with electroshock. Issues in Mental Health Nursing, 32(7), 457472. doi: 10.3109/01612840.2011.583810. 
van Daalen-Smith, C., Adam, S., Breggin, P. \& LeFrançois, B. (2014). The utmost discretion: How presumed prudence leaves children susceptible to electroshock. Children \& Society, 28, 205-217.

Whitaker, R. (2002). Mad in America: Bad science, bad medicine, and the enduring mistreatment of the mentally ill. New York: Basic Books.

Wojitowicz, B., Hagen, B., \& van Daalen-Smith, C. (2014). No place to turn: Nursing students' experiences of moral distress in mental health settings. International Journal of Mental Health Nursing, 23, 257-264. 